\title{
CAMINHOS TEÓRICOS E OPÇÕES METODOLÓGICAS NA PESQUISA COM CRIANÇAS NAS INTER-RELAÇÕES DE GÊNERO E SEXUALIDADE NA EDUCAÇÃO FÍSICA
}

Ileana Wenetz ${ }^{1}$

\section{ALGUMAS PALAVRAS PARA INICIAR...}

Para início de conversa, cabe perguntar: que escolhas tenho realizado para pesquisar, na educação física, crianças e articulação de gênero e sexualidade? A resposta a essa pergunta se direciona a múltiplas escolhas, que faço atualmente, observando que refletem minha trajetória desde meus tempos aluna da pós-graduação, até os de minha atuação como professora da Universidade Federal do Espírito Santo (Ufes), no curso Educação Física e no de pós-graduação em Psicologia Institucional, afora minha participação em grupos de pesquisa com os quais me articulo.

Fiz parte dos grupos Geerge ${ }^{2}$ e Gesef $^{3}$, na UFRGS, e, atualmente, do Geps ${ }^{4}$ e do Lesef $^{5}$, na Ufes. Esta menção é fundamental porque explica e identifica meu modo de pensar a respeito das produções em gênero e sexualidade no cenário brasileiro. Também referenda o modo de pensar, ou a opinião, de todas as que me precederam (e que me formaram), com inter-relações que mantenho até hoje em minha prática pedagógica.

No presente artigo, tenho por objetivo desenvolver algumas ideias que se têm configurado em meu percurso acadêmico, mas vinculadas ao desdobramento das escolhas

\footnotetext{
${ }^{1}$ Licenciada em Educação Física pela Facultad de Educación y Salud (FES/IPEF) Argentina. Especialista em Pedagogia do Corpo e da Saúde pela EsEF/UFRGS. Mestre e Doutora em Ciências do Movimento Humano pela EsEF/UFRGS. Pós-doutora no Programa Interdisciplinar de Ciências Humanas da UFSC. Professora Adjunta do Departamento Ginástica do Centro de Educação Física e Deportes da Universidade Federal de Espírito Santo (UFES). Professora da Pós-graduação em Psicologia Institucional (UFES). Participante do Laboratório de Estudos em Educação Física (LESEF) da UFES e participante do Grupo de Estudos e Pesquisas em Sexualidade (GEPSS).

${ }^{2}$ Grupo de Educação e Relações de Gênero (UFRGS).

${ }^{3}$ Grupo de estudos Socioculturais em Educação Física (UFRGS).

${ }^{4}$ Grupo de Estudos e Pesquisa em Sexualidades (Ufes).

${ }^{5}$ Laboratório de Estudos em Educação Física (Ufes).
}

Vol. 02, N. 02, Abr. - Jun., 2019 · www.revistas.unilab.edu.br/index.php/rebeh 
teóricas e políticas e, por consequência, às estratégias metodológicas utilizadas com crianças.

2 SOBRE O DEBATE E SUAS NUANCES

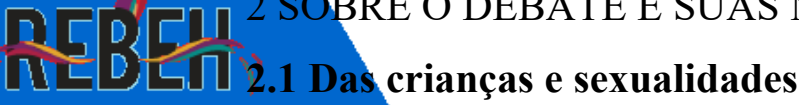

De alguma maneira, centralizo o debate em três grandes eixos, que constituem os pressupostos teóricos: 1. aprendizagem sobre gênero, sexualidade e corpo em diversos espaços (escolares e não escolares); 2. problematização das crianças no espaço público nas práticas corporais, lúdicas ou de lazer e 3. concepção de educação do corpo na cidade.

Para poder desenvolver as nuances desses eixos, ou pressupostos, início o debate delimitando o conceito de infância. Ao falar de infância, é necessário definir algumas características dessa fase da vida, mas gostaria de destacar algumas delas e mudar o foco, já que se trata de compreender a infância não como uma etapa a ser vivida, mas como cada criança é entendida em sua pluralidade e diversidade.

Jorge Larrosa entende ser possível pensar a infância como "algo que nossos saberes, nossas práticas e nossas instituições já capturaram: algo que podemos explicar e designar, algo sobre o qual podemos intervir, algo que podemos acolher" (1999, p. 184). A infância constitui um objeto de estudo sobre o qual trabalhamos e do qual buscamos nos aproximar. Porém, continua o autor, também é possível pensar a infância como "o outro: aquilo que, sempre além de qualquer tentativa de captura, inquieta a segurança de nossos saberes" (1999, p. 183). Isto lhe permite afirmar que as crianças são "esses seres estranhos dos quais nada se sabe, esses seres selvagens que não entendem nossa língua" (1999, p. 183). Tentarei operar simultaneamente com estes dois sentidos: por um lado, os aspectos simples que todos nós conhecemos sobre a infância, que foram e continuam sendo objeto de estudo (e da convivência cotidiana); por outro, procurarei explorar todas as possibilidades de compreender essa infância, cuidar dela e entendê-la, embora consciente de que nunca a poderemos esgotar.

Autores como Narodowski (1998) e Postman (1999) consideram que a infância, do modo como a concebemos hoje, no sentido de a criança estar em um período particular, de precisar de cuidados especiais e dever ser protegida, chegou ao fim, desapareceu. Postman (1999) entende que é possível observar nesse desaparecimento a configuração de uma nova infância. Uma das instâncias responsáveis por essa transformação seria a 
influência da mídia atualmente na vida das crianças, fazendo com que elas aprendam muitos significados sociais através dos meios de comunicação.

Entender a infância como uma construção cultural e histórica significa

compreendê-la como um processo contínuo e imbricado dentro de um espaço cultural [1]느 D كا específico. Nessa direção, Clarice Cohn (2005, p. 21) destaca a necessidade de entender

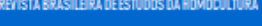
uma antropologia da criança e não de uma infância, pois a infância "é um modo particular, e não universal, de pensar a criança", o que nos permite falar dela como uma etapa ou uma construção social e histórica do Ocidente. Ao contrário, a antropologia da criança possibilita "perceber a criança como um sujeito social” (2005, p. 11). Esta diferenciação ajuda a focar minha análise, relativizando a infância como uma etapa concebida a priori.

Para Moysés Kuhlmann (2001, p. 16), a infância compreende um processo tanto histórico quanto social e não pode ser entendida como "homogênea, estável ou natural", porque, dentro dela, localizamos diferentes significados construídos em um contexto específico, que não é linear. Tal processo nos permite mapear as nuances culturais e a configuração de suas características, focando cada criança no particular, não partindo do pressuposto de que todas são iguais.

Para pensar os encaminhamentos metodológicos com crianças, utilizei métodos e/ou estratégias que me permitiram observá-las, provocar suas falas e escutá-las. ${ }^{6}$ No entanto, estou ciente de que tais práticas não me permitem afirmar que apresento 'uma verdade' sobre elas. Operei com a ideia de que não é possível 'dar voz' às crianças como se elas não tivessem essa possibilidade antes das pesquisas realizadas. Mapeando as expressões, as falas e os significados por elas utilizados, pode-se compreender como produzem/reproduzem diversos discursos sobre elas próprias, inclusive sobre o cotidiano que vivenciam. Tais expressões, falas e significados estão atravessados por muitos discursos e visões de mundo diferentes das que circulam na família, na mídia, na escola, entre os adultos e entre outras crianças com as quais brincam. Ou seja, tais expressões, falas e significados são invenções que se entrelaçam e se constroem na cultura em que as crianças vivem.

Cohn (2005) destaca que a criança, independentemente do espaço cultural, convive com adultos e com outras crianças, e justamente essa interação permite a construção do sujeito e de suas relações. Podemos perguntar-nos como acontece essa construção cultural. Bujes (2002, p. 20) entende não ser hoje possível pensar a infância

\footnotetext{
${ }^{6}$ Faço referência, aqui, tanto à minha dissertação (2005), quanto à minha tese (2012).

Vol. 02, N. 02, Abr. - Jun., 2019 - www.revistas.unilab.edu.br/index.php/rebeh
} 
separada de um dispositivo pedagógico, ou seja, de "um conjunto de estratégias do qual poder se vale para investir-se $n a$ e sobre a infância". Nessa direção, é possível falar de ‘outras infâncias' e não de uma única, pois, segundo a autora, “foi uma sociedade do tipo disciplinar que, no comando social, estabeleceu uma série de dispositivos ou aparelhos [U]느 5$]$ que produziram ou regularam costumes, hábitos e práticas que se empenharam na

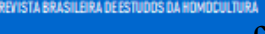

fabricação de novos tipos de sujeitos" (2002, p. 20). Desse modo, a infância só teria existido como um ideal moderno, no qual se pretendia um sujeito infantil, mas este seria, em sua concretização, sempre "parcial, imperfeito ou incompleto" (2006, p. 219).

A referida construção do sujeito infantil ocorreu por meio da disciplina, que atuou através de instituições como a família e, principalmente, a escola. Castro (2009, p. 110), apoiando-se nas ideias de Foucault, afirma que podemos operar com a disciplina em dois sentidos: "na ordem do saber" (forma discursiva de controle da produção de novos discursos) e "na ordem do poder (conjunto de técnicas em virtude das quais os sistemas de poder têm por objetivo e resultado a singularização dos indivíduos)."

Nessa direção, ao compreendermos o sujeito criança, podemos refletir e constatar como não são seres assexuados, sem corpo ou inocentes. Weeks destaca que a sexualidade constitui uma "série de crenças, comportamentos, relações e identidades construídas e historicamente modeladas" (1999, p. 43). Além de ser uma questão pessoal, é social e politicamente "construída, ao longo de toda a vida, de muitos modos, por todos os sujeitos" (LOURO, 1999, p. 11). Neste sentido, ainda segundo a mesma autora, ao compreender que a sexualidade é aprendida em um momento histórico específico, podemos entender como opera também como um "dispositivo histórico" (1999, p. 11) 7 . Desse modo, tem "tanto a ver com nossas crenças, ideologias e imaginações, quanto com nosso corpo físico" (1999, p. 38), pois os diversos significados que atribuímos à nossa sexualidade, e também ao nosso corpo, são "socialmente organizados" e são, ainda, amparados por uma "variedade de linguagens que buscam nos dizer o que o sexo é, o que ele deve ser e o que ele pode ser" (1999, p. 43).

Em nossa organização social, entende-se a criança como assexuada; por consequência, não se pode falar sobre isso. Nesse contexto, a sexualidade infantil foi

\footnotetext{
7 Foucault (2002a, p. 244) define o dispositivo da sexualidade como "um conjunto decididamente heterogêneo que engloba discursos, instituições, organizações arquitetônicas, decisões regulamentares, leis, medidas administrativas, enunciados científicos, proposições filosóficas, morais, filantrópicas. Em suma, o dito e não dito são elementos do dispositivo. O dispositivo é uma rede que se pode estabelecer entre estes elementos".
} 
criada em contraposição à sexualidade do adulto, sendo absorvida no espaço da família, na qual não existe nem deve haver manifestação sobre ela. Assim, no século XVIII, a masturbação infantil foi abordada e reorganizada a partir de novas concepções das

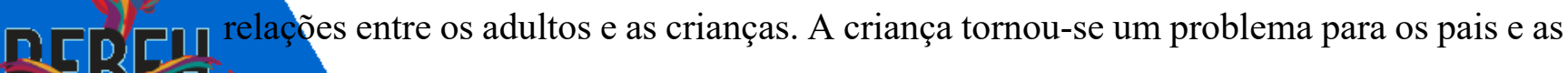

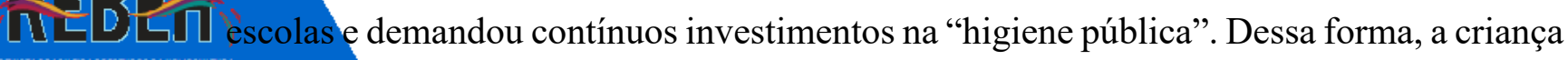

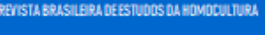

passou a ser alvo e instrumento de poder, precisando ser continuamente vigiada (FOUCAULT, 2002a, p. 232).

Para Deborah Britzmann (1996, p. 74), refletir sobre "os significados contraditórios dessas categorias [criança e adulto] em termos de sexualidade exige que lidemos com as representações generificadas e sexuais - as aceitas e as rejeitadas - que circulam, formal e informalmente, nas escolas". Considerando o contexto escolar, e apesar de tanto a sexualidade quanto o corpo constituírem e fazerem parte dos espaços institucionais, Bell Hooks (1999, p. 115) entende que "o mundo público da aprendizagem institucional [ainda] é um lugar onde o corpo tem que ser anulado, tem que passar despercebido".

Desse modo, na escola circulam diversas identidades. Em relação a esse aspecto, Britzman (1996) diz que a escola não somente produz diversas formas de conhecimento, mas também "relações particulares de desigualdade, ao longo de divisores de raça e de gênero, mas, mais imediatamente, produz e organiza, de forma coincidente, as identidades raciais, culturais e generificadas dos/as estudantes" (1996, p. 72).

Vejamos agora como se podem pensar essas aprendizagens em diversos espaços.

\subsection{Das aprendizagens e dos espaços}

Ao pensar como as crianças aprendem, imediatamente refletimos sobre a escola, mas podemos pensar em quais outros espaços eles aprendem, pois, ampliado o conceito do termo educação, e em sua relação com as vivências em outros âmbitos da vida cotidiana, a educação pode acontecer em outros espaços - não necessariamente no espaço escolar -, não precisando ter como intenção ou objetivo educar.

No sentido tradicional, a educação aconteceria em espaços formais de educação, ou seja, nas escolas, nas quais - através do estabelecimento de objetivos previamente determinados, como planejamento de conteúdos, utilização de determinadas metodologias e avaliações - o aluno ou a aluna aprenderia somente os conteúdos préestabelecidos. Tais espaços disciplinares vão constituindo o modo como a infância opera 
dentro do espaço da escola. Em relação a este aspecto, Bujes (2006, p. 221) reflete: “[...] pode-se perceber, então, como a disciplina funcionou/funciona para exercer o seu poder sobre o corpo das crianças através de estratégias e operações de disciplinamento. Ela as enclausura, isso é, as isola para conhecê-las e intervir [...]."

Nessa direção, há hoje novas formas de subjetivação da infância associadas a

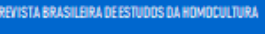
outros espaços, além da escola, pois temos "um conjunto de circunstâncias associadas à vida urbana" que tem modificado as vivências das crianças. Assim, ainda segundo Bujes (2006, p. 224), trata-se de "novas formas de confinamento" que "atingem as formas de viver das crianças, criam interdições aos seus movimentos, espaços que lhe são proibidos, impedimentos de circulação, um lá fora que não pode ser visitado...”.

A autora destaca quatro novas formas de confinamento: a primeira refere-se aos condomínios residenciais, com espaços de lazer e zonas de compras nos quais não se justifica a criança sair; a segunda alude às prisões femininas, locais onde as crianças permanecem através de benefícios judiciais pela amamentação; a terceira reporta-se aos campos de refugiados em zonas de guerra; e a quarta, as casas de favelas, espaços onde acontecem confinamentos nos quais não é possível ir à rua, por questões de segurança (BUJES, 2006).

Desse modo, temos, por um lado, aprendizagens diferenciadas que acontecem segundo espaços e condições específicas de confinamento. Por outro lado, temos aprendizagens ou saberes que circulam e são aprendidos em diferentes espaços, sejam de confinamento ou não. Cabe destacar que, tanto os de confinamento quanto os abertos, como, por exemplo, a rua e as praças, serão entendidos aqui como espaços de aprendizagem não formais, pois as aprendizagens acontecem independentemente de nossas vontades, e as crianças podem vivenciar as liberdades de diferentes maneiras.

Considerando esses novos espaços não formais de aprendizagem (ruas, praças, músicas, brinquedos, etc.), Shirley Steinberg (1997) entende que podemos chamá-los de pedagogias culturais, ${ }^{8}$ que constituem novos artefatos culturais por permitirem diversos modos de aprendizagem para as crianças, já que se referem a uma educação que ocorre em diferentes locais, não limitada ao espaço físico da escola.

\footnotetext{
${ }^{8}$ As pedagogias culturais caracterizam-se, também, por aquilo que a autora definiu como "Kindercultura": uma cultura particular enraizada no prazer, produzida por grandes corporações - com um alto poder econômico - que viabilizam formas e maneiras particulares e hegemônicas de 'ser'.
} 
Assim, se pretendemos conhecer as crianças, "essa pedagogia nos dá uma linha direta [...] com suas percepções de si mesmas e do mundo" (1997, p. 141). Ao se encontrar com o conhecimento oficial da escola, permite novas formas de aprendizagem e de construção da infầncia.

Atualmente, além dos especialistas e das áreas de estudo específicas, há também uma série de produtos direcionados a diferentes grupos e sujeitos. Trata-se de um conjunto infinito de videogames, roupas, músicas, acessórios, guloseimas, filmes, desenhos, sapatos, programas de TV, jornais, revistas, anúncios, livros e esportes disponibilizados indistintamente a quem os procurar ou adquirir. Sarmento (2005, p. 366) acrescenta que a inclusão desses jogos modificou “o tipo de brinquedos e o uso do espaçotempo lúdico das crianças, gerou novas linguagens e desenvolveu apetências de consumo que não podem deixar de ser considerados na análise contemporânea das culturas e das relações de pares das crianças".

A afirmação acima nos permite refletir sobre como se vem configurando a educação da criança através do tempo. Sarmento, respondendo a Delgado e a Müller (2006, p. 17), em entrevista, afirma:

[...] o lugar da infância na contemporaneidade é um lugar em mudança. A modernidade estabeleceu uma norma da infância, em larga medida definida pela negatividade constituinte: a criança não trabalha, não tem acesso direto ao mercado, não se casa, não vota nem é eleita, não toma decisões relevantes, não é punível por crimes (é imputável). Essa norma assenta um conjunto estruturado de instituições, regras e prescrições que se encarregam da 'educação' da criança, especialmente a escola e a família.

Ao falar de crianças, a norma estabelecida é geralmente a de que elas não participam das responsabilidades do mundo adulto. Assim, teriam mais tempo disponível para as brincadeiras. Em alguns casos, porém, as obrigações podem ser reconfiguradas: o cuidado de irmãos menores, as atividades do lar e, inclusive, o ir à escola. Dependendo da condição econômica de uma família, a criança ainda pode ter uma série de obrigações traduzidas em aulas extras (línguas, esportes, etc.).

Nesse contexto de diferentes vivências, tanto de lazer quanto de aprendizagem, ao considerar a aprendizagem que acontece em outros espaços, poder-se-ia afirmar que é possível observar processos de educação em momentos ou espaços não oficiais ou de lazer, partindo do pressuposto de que as atividades desenvolvidas no espaço do lazer sempre educam, independentemente de isso ser ou não o objetivo do professor. De acordo 
com Stigger (2009, p. 76), "a cultura, e juntamente com ela a educação, são aspectos que atravessam diferentes dimensões da vida das pessoas, incluindo aí as atividades que se inserem no contexto do lazer. A partir disso, argumentarei no sentido de que atividades de lazer sempre educam [...]" (grifos do autor). Isso pode acontecer em momentos

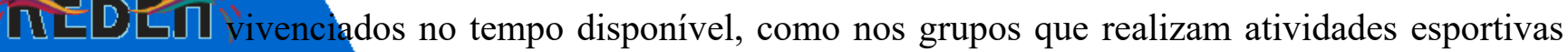

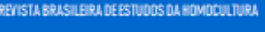
e/ou recreativas, observando-se diferentes estratégias e características de cada grupo, determinando uma 'cultura' do grupo sobre o sentido que os sujeitos atribuem a suas práticas.

Desse modo, dentro do campo de estudos do lazer, acontecem diversas discussões internas e externas que não pretendo desenvolver neste tópico, pois entendo que o lazer constitui um campo do saber, no qual se fazem presentes as relações de poder. Sant'Anna (1992, p. 56) entende que a área do lazer, num primeiro olhar, poderia parecer um "corpus sem fissuras", como se fosse um saber "homogêneo, isento de contradições". Neste sentido, apesar das discussões, trago à tona o sentido educativo que podemos observar no espaço do lazer.

As crianças conformam-se num processo tanto criativo quanto reprodutivo, no qual se daria visibilidade à compreensão de que elas têm capacidade de "formular interpretações da sociedade, dos outros e de si próprias, da natureza, dos pensamentos e dos sentimentos, de o fazerem de modo distinto e de o usarem para lidar com tudo o que as rodeia" (SARMENTO, 2005, p. 373). Aqui, as crianças não estariam sendo entendidas como "objetos manipuláveis, vítimas passivas ou joguetes culturais neutros" (SARMENTO, 2005, p. 373), mas como seres capazes de criar e ressignificar sentidos sociais. Mas qual é a relação entre o espaço da brincadeira (sejam espaços escolares ou não) e as crianças? Para falar deles, devemos compreender como se entende o espaço da rua.

Segundo Lefebvre (2002), a rua tem aspectos favoráveis, sendo um "[lugar] do encontro, sem o qual não existem outros encontros possíveis nos lugares determinados (cafés, teatros, salas diversas). Esses lugares privilegiados animam a rua e são favorecidos por sua animação, ou então não existem" (2002, p. 29). Lugares como bares, teatros e outros espaços públicos permitem o encontro e a convivência dos adultos, e não necessariamente constituem espaços para crianças. Rabelo Gomes et al. (2008, p. 55) entendem ser a rua um espaço no qual a criança deve ser integrada, porque "é na rua que se exerce, com maior força, a sociabilidade infantil, que tem na atividade do brincar sua expressão, no interior do grupo de pares". Assim, as crianças brincam na rua, a Vol. 02, N. 02, Abr. - Jun., $2019 \cdot$ www.revistas.unilab.edu.br/index.php/rebeh 
ressignificam e conformam de diferentes modos, pois, "ao ocupar as ruas para os jogos coletivos, as vielas para o brincar de bola de gude, os locais vazios para a pipa, a criança investe os espaços públicos de novos significados" (GOMES et al., 2008, p. 56). Brincando na rua, crianças fazem amizades e compartilham esses espaços que, num

a restrição que ocorre dentro da casa, na presença de uma autoridade adulta; a amplidão do espaço, que permite tanto sua construção quanto sua exploração; a oportunidade de brincar com um maior número de parceiros; entre outros. Essas variantes de possibilidades de experiência nas brincadeiras permitem diversas aprendizagens às crianças. Também devemos considerar outras atividades lúdicas (como subir em árvores ou brincadeiras diferentes daquelas realizadas em suas casas) e a prática de esportes como um grande leque.

Gostaria, aqui, de destacar como parece haver brincadeiras diferentes que acontecem em diversos espaços, pois, segundo as características e as possibilidades de tal espaço, seja em casa ou na rua, a criança aprende na convivência práticas culturais diversas que fazem parte da cultura na qual ela se insere. Além disso, algumas práticas vão mudando e configurando-se no tempo, assim como as crianças podem aprender uma determinada brincadeira de maneiras diferentes.

Em relação a como algumas práticas vão mudando no tempo e como estas são aprendidas de diversos modos, Gomes et al. (2008) entendem que, atualmente, a prática do esporte tem uma nova configuração, deslocada para as atividades pedagogicamente planejadas, e isto, na maioria das vezes, promove atividades separadas por gênero. Esta maneira de se organizar encontra-se presente nas brincadeiras determinadas para meninos e meninas. Dessa maneira, "se perde ou se torna menos operante quando o acesso aos espaços públicos não é mais possível, e o jogo - quase que todos os jogos possíveis de serem jogados - é pré-demarcado pela sua circunscrição a espaços institucionais" (2008, p. 63). Desse modo, segundo as autoras, práticas esportivas estabelecem separação por gênero, mas a brincadeira no espaço não institucional permitiria uma experiência diferenciada, ou a partir de outras formas de organização, e não necessariamente pela separação por gênero. Mas qual é a relação do corpo da criança com o espaço da cidade?

\section{A CIDADE: ESPAÇO DEMOCRÁTICO?}


A cidade é para todos! Será que é possível sustentar esta afirmação? A cidade é para todos? Será que todos, adultos e crianças, circulam pelo espaço da mesma maneira? Espaços, urbanização, arquitetura, organização, tempo, deslocamentos, crianças, sociabilidade e cidade... Em um breve olhar, podemos afirmar serem poucas as relações

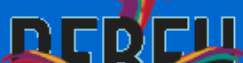

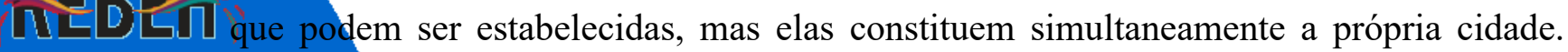

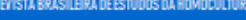

Foucault (2010) afirma que a arquitetura possibilita um exercício da liberdade, na medida em que ela "pode produzir e produz efeitos positivos quando as intenções libertadoras da arquitetura coincidem com a prática real da gente em exercício de sua liberdade" (2010, p. 94). Afinal, a prática de liberdade não é outorgada a priori pela natureza dos objetos, mas pelo próprio exercício dos sujeitos (com a arquitetura operando no mesmo sentido). Nessa direção, na arquitetura de um lugar, pode-se observar como uma "textualidade" conformada por uma ordem "que transmite, através de seus traçados e símbolos, uma determinada semântica, ou seja, uma cultura" (ESCOLANO, 2000, p. 102).

Qual é o exercício de liberdade que uma criança pode ter na sua cidade? Certamente, é menor daquela que o adulto tem. Não podemos esquecer que esse exercício de liberdade pode ser modificado segundo a cultura à qual pertence. Entende-se, aqui, por cultura, um campo de constantes lutas, ações, contestações, aceitação e resistências, em que os sujeitos se conformam em grupos diferentes, com particularidades específicas. Dentro desses grupos, os sujeitos interagem com outras formas de classificação social, cada uma delas com seus próprios traços, capazes de deixar suas marcas, como raça, etnia, nacionalidade, geração, classe, entre outras. Tais marcas configuram uma hierarquia de poder; ${ }^{9}$ são significadas por relações de poder e hierarquizadas. Elas adquirem significados através da e na cultura, e não fora dela. Marcas que as crianças aprendem desde muito cedo.

Louro (2000, p. 61) destaca supormos que “as marcas devem nos 'falar' dos sujeitos. Esperamos que elas nos indiquem - sem ambiguidade - suas identidades". Por esse motivo, ficamos "desconfortáveis" se não acertamos na leitura dessas marcas,

\footnotetext{
${ }^{9} \mathrm{O}$ poder é produtivo, disperso, descentralizado e penetra na vida cotidiana dos sujeitos, atingindo seus corpos, "não para supliciá-lo[s], mutilá-lo[s], mas aprimorá-lo[s], adestrá-lo[s]" (FOUCAULT, 2002b, p. 16). Procura-se, por meio do poder, disciplinar, fabricar corpos submissos e "dóceis", pois "a disciplina aumenta as forças do corpo (em termos econômicos de utilidade) e diminui essas mesmas formas de forças (em termos políticos de obediência)" (2002b, p. 119). O poder ainda é exercido de forma múltipla. Ele submete e disciplina, mas também se exerce de forma dispersa e cria uma rede de forças, como condição de funcionamento; estabelece relações de resistência, linhas de fuga, como, por exemplo, quando se observam as diferentes atitudes/comportamentos/expressões das crianças que escapam daquilo que a escola estabelece como normas. Foucault desconstrói o sentido tradicional outorgado ao poder; desfaz o par opressor-oprimido em que o poder é vertical. Não obstante, o autor entende que o dominador exerce uma força, a qual, de certa forma, é negociada/aceita/rejeitada pelo oprimido.
} 
pretendendo que elas sejam fixas e inalteráveis, pois nós simplesmente "esquecemos" que identidade [...] é uma atribuição cultural; que ela sempre é dita e nomeada no contexto da cultura. Esquecemos que os corpos são significados, representados e interpretados culturalmente" (2000, p. 62).

Haesbaert (1999) entende que toda identidade implica uma territorialização, que, por sua vez, possibilita certa permanência identitária produzida nos diferentes grupos sociais e através das relações de poder, mas "ela nunca é uma; é múltipla" (p. 175). Na convivência da cidade, produzem-se múltiplos sentidos nas negociações culturais ou em atributos identitários. Segundo Silva e Benhur (s/d, p. 3), é nesse jogo de negociações de identidade que se produzem "múltiplas apropriações sociais em grande escala (em micropartes do espaço urbano)". Nessa direção, procura-se cristalizar atributos culturais das identidades. Estas "disputam seu lugar no espaço, procuram se territorializar, definindo as pessoas pertencentes àquele grupo e àquele território e segregando ou sendo segregadas de/por outros" (s/d, p. 3). Continuando com as ideias dos autores, as microterritorializações são produzidas no contexto do espaço urbano e são representadas “pelos processos de identificação que se produzem e se reproduzem pelas práticas culturais do microagregado socioespacial em diferenciação com outros” (s/d, p. 6). Desse modo, cada "agregado social territorializado no espaço urbano é constituído por sua identificação coletiva e sua cultura” (s/d, p. 6).

Quando escrevo espaço, não faço referência somente ao cenário e ao tempo como "um fundo contínuo ao longo do qual os acontecimentos se desenrolam" (VEIGA-NETO, 2002, p. 207). Entendo que as diferentes formas pelas quais nos relacionamos com o espaço não são universais, mas aprendidas e construídas, imbricadas de sentidos de acordo com a sociedade em que nos encontramos. Assim, o espaço é diferente, heterogêneo, dinâmico, histórico e possui elementos que se articulam, justapõem e sobrepõem uns aos outros. A articulação da relação entre o sujeito e sua espacialidade permite entender suas dinâmicas e seu caráter transitório e construído.

O espaço se tece na vida da cidade; ele se constrói em múltiplos sentidos e nunca é neutro. A construção de um espaço próprio faz parte do pressuposto de que ele está sempre disponível para tornar-se lugar. Mas existem também impedimentos para isso, pois todas as pessoas não podem ocupar todos os lugares simultaneamente, tendo-se, assim, uma luta ou negociação por sua ocupação. As sociedades tentam controlar, organizar, geometrizar e segmentar os espaços, pois, segundo Foucault (2002), como 
citado na epígrafe desta seção, é necessário "fazer uma história dos espaços", que seria realizar uma "história dos poderes" que nele operam.

Jacobs (2009) entende que a cidade não tem espaços preparados para as crianças,

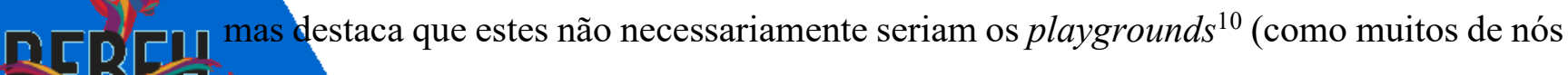
[1]는 $5 \sqrt{1}$ poderíamos pensar). Ainda Oliveira et al. (2008), ao investigar as crianças no seu espaço

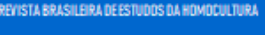
social, entendem que um contexto urbano permite observar as formas que para nós são mais comuns, como "ruas, parques, espaços de lazer, experiências de brincadeiras, etc." (2008, p. 16). Apesar dessas estruturas nas cidades, devemos considerar outros elementos, como, por exemplo, "suas práticas formas de usos e apropriações dos espaços (públicos e privados), ao mesmo tempo, como [os sujeitos] anunciam, tensionam e ressignificam os espaços na metrópole (2008, p. 16).

Observando os vários playgrounds e refletindo sobre como as crianças poderiam não só fazer uso desses espaços, mas também ressignificá-los, só resta perguntar: Onde as crianças brincavam? Por que esses espaços não 'aglutinavam' de algum modo as crianças observadas? As crianças encontram-se nos espaços das escolas e nos espaços confinados da casa. Poucas crianças circulam sozinhas pelo espaço público que se tornou anônimo e sinônimo de uma sensação geral de insegurança. ${ }^{11}$

No contexto dessas cidades, Simmel, em sua célebre conferência de 1903, já destacava que "os problemas mais profundos da vida moderna brotam da pretensão do indivíduo em preservar a autonomia e a peculiaridade de sua existência frente às superioridades da sociedade, da herança histórica, da cultura exterior e da técnica da vida [...]” (2005, p. 577). Assim, essa cultura exterior foi sendo modificada pelo indivíduo nas cidades através da transformação da natureza; a "cidade constitui sua própria natureza ao destruí-la" (VAZ, 2010, p. 35), pois ela produz simultaneamente dois tipos de experiências humanas. Por um lado, o movimento veloz, os horários e as regras. Por outro lado, produz o tédio e a urgência de se liberar dele, porque é no espaço da cidade que há lugar para a luta contra o tédio. Nessa direção, como afirma Vaz, "não é por acaso que o lazer se torna um tema tão importante. O homem urbano provavelmente tem no tédio um de seus maiores inimigos - não pode haver tempo 'morto' e, por isso, é tão obrigatório divertir-se, gozar a tudo custo (2010, p. 40).”

\footnotetext{
${ }^{10}$ Playgrounds são praças de jogos para crianças que disponibilizam brinquedos, como trepa-trepa, balanço, etc.

${ }^{11}$ Para ver mais detalhes sobre o debate das crianças no espaço público, ver Wenetz (2012).
}

Vol. 02, N. 02, Abr. - Jun., $2019 \cdot$ www.revistas.unilab.edu.br/index.php/rebeh 
A cidade transforma sua natureza e ela tem provavelmente diversas formas de se apresentar. Poderíamos considerar a primeira intrínseca à cidade ou relativa ao espaço urbano, por conformar parques ou jardins, que têm por objetivo restituir de alguma maneira a natureza perdida pelas construções ou pela "civilização", na ideia de tornar [D는 $5 \Omega$ aquele espaço mais humano. A segunda maneira de a natureza ser concebida ou

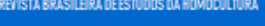

apresentada pode ser definida como externa à própria cidade, enquanto espaço aberto, como campos, trilhas, praias e montanhas que permitem relaxar e evitar o tempo frenético e cronometrado (VAZ, 2010).

Antes de continuar com essa questão, gostaria de destacar outro caminho para olhar a cidade. Faz-se necessário pensar sobre as vivências das pessoas no ambiente urbano, sobre como as pessoas veem tais espaços, as relações construídas e estabelecidas com o local, e, mais especificamente, suas lembranças. A referência ao espaço da cidade que buscamos na memória parece relacionar-se com a intimidade que se tinha com tal espaço - fosse ele privado ou público - que considerávamos nosso. Era conhecido; sabiase sobre ele em seus detalhes, em suas formas e funcionamentos; havia laços com ele.

A cidade é um espaço de uma vivência e experiência corporal de que não podemos nos despir, pois também fazemos parte dela. Assim, em nosso cotidiano, transitando por diferentes espaços entre a casa e o trabalho, e em momentos de lazer, constrói-se "uma pedagogia dos gestos que a ninguém exclui", porque é justamente nesse espaço que "os sentidos do corpo são educados, treinados para reagir" (VAZ, 2010, p. 39), simultaneamente outorgando um outro olhar e outros sentidos a nossas práticas.

\section{PALAVRAS FINAIS PARA NÃO CONCLUIR...}

Desenvolvi, neste texto, alguns pressupostos teóricos-metodológicos que afetam e envolvem a pesquisa e os modos de operar com crianças. Dentre esses pressupostos, alguns elementos foram mais detalhados do que outros, como, por exemplo, a noção de infância, a compreensão da criança em sua diversidade, suspeitando de um sentido único ou verdadeiro ou de uma natureza assexuada. Dita compreensão nos permite tensionar a bipolaridade e simultaneamente a norma sobre sentidos ou atribuições tanto ao masculino quanto ao feminino. Destaco, nessa conclusão, alguns recursos metodológicos pouco explorados no texto, como utilizar metodologias que permitam ouvir pessoas, sobretudo crianças, deter-se e com elas e com elas conversar... Para ser mais específica, recomendo metodologias como etnografias, cartografias e outros métodos que permitam a Vol. 02, N. 02, Abr. - Jun., 2019 - www.revistas.unilab.edu.br/index.php/rebeh 
observação detalhada do convívio com os sujeitos participantes da pesquisa. Além de utilizar técnicas como entrevistas semiestruturadas, abertas ou narrativas, proponho questionários abertos, histórias de vida, grupos focais, etc.

Nessa articulação, torna-se também necessário operar com as categorias de gênero

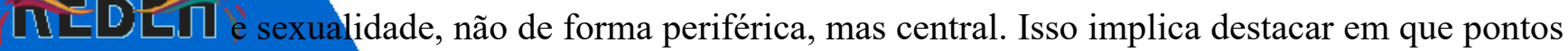

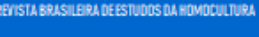

ou elementos as categorias se afastam e/ou se aproximam entre si para operar com nossos dados. Além disso, é preciso articular tais categorias a outros marcadores sociais, como geração, religião, etnia, etc., pois é nessas nuances que identificaremos o tensionamento e os silenciamentos naturalizados nas aprendizagens do cotidiano vivenciado pelas crianças.

\section{REFERÊNCIAS}

BRITZMAN, Deborah. O que é esta coisa chamada amor: identidade homossexual, educação e currículo. Educação \& Realidade, Porto Alegre, v. 21, n. 1, p. 71-96, jan./jun. 1996.

BUJES, Maria Isabel. Criança e brinquedo: feitos um para o outro? In: VORRABER, Marisa Costa (Org.). Estudos culturais em educação: mídia, arquitetura, brinquedo, biologia, literatura, cinema... Porto Alegre: Editora da UFRGS, 2000. p. 205-228.

Outras infâncias? In: SOMER, Luis Henrique; BUJES, Maria Isabel Edelweiss

(Orgs.). Educação e cultura contemporânea: articulações, provocações e transgressões em novas paisagens. Canoas: Ed. ULBRA, 2006.

CASTRO, Edgardo. Vocabulário de Foucault: um percurso pelos seus temas, conceitos e autores. Belo Horizonte: Autêntica Editora, 2009.

COHN, Clarice. Antropologia da criança. Rio de Janeiro: Jorge Zahar, 2005.

COSTA, Rogério Haesbaert da. O mito da desterritorialização: do "fim dos territórios" à multiterritorialidade. Rio de Janeiro: Bertrand Brasil, 2007.

DELGADO, Ana Cristina Coll; MÜLLER, Fernanda. Infâncias, tempos e espaços: um diálogo com Manuel Jacinto Sarmento. Currículo sem fronteiras, v. 6, n. 1, p. 15-24, jan./jun. 2006.

ESCOLANO, Agustín. El espacio escolar como escenario y como representación. Teias, Rio de Janeiro, v. 1, n. 2, p. 99-133, jul./dez. 2000.

FOUCAULT, Michel. Vigiar e punir. Petrópolis: Vozes, 2002a.

Microfísica do poder. Rio de Janeiro: Edições Graal, 2002b.

El cuerpo utópico: las heterotopias. Buenos Aires: Nueva Visión, 2010.

HAESBAERT, R. C da. Identidades territoriais. In: ROSENDHAL, Z.; COOREA, R. L. Manifestações da cultura no espaço. Rio de Janeiro: Ed: UERJ, 1999. p. 1-9. 
GOMES, Ana Maria Rabelo; GOUVEA, Maria Cristina Soares de. A criança e a

cidade: entre a sedução e o perigo. In: DEBERTOLI, José Alfredo Oliveira; MARTINS, Maria de Fátima Almeida; MARTINS, Sérgio (Org.). Infâncias na metrópole. Belo

Horizonte: Editora UFMG, 2008. p. 47-69.

HOOKS, Bell. Eros, erotismo e o processo civilizatório In: LOURO, Guacira Lopes

(Org.). O corpo educado: pedagogias da sexualidade. Belo Horizonte: Autêntica Editora, 1999.

JACOBS, Jane. Morte e vida de grandes cidades. São Paulo: Martins Fontes, 2009. (Coleção Mundo de Arte).

KUHLMANN, Moysés Junior. Infância e educação infantil: uma abordagem histórica. Mediação: Porto Alegre, 2001.

LARROSA, Jorge. Pedagogia profana: danças, piruetas e mascaradas. Belo Horizonte: Autêntica Editora, 1999.

LEFEBVRE, Henri. A revolução urbana. Belo Horizonte: Editora UFMG, 2002.

LOURO, Guacira Lopes (Org.). O corpo educado: pedagogias da sexualidade. Belo Horizonte: Autêntica Editora, 1999.

LOURO, Guacira Lopes. Corpo, escola e identidade. Educação \& Realidade, Porto Alegre, v. 25, n. 2, p. 59-75, jul./dez. 2000.

POSTMAN, Neil. O desaparecimento da infância. Rio de Janeiro: Graphia, 1999.

SANT'ANNA, Denise Bernuzzi. O prazer justificado: história e lazer (São Paulo, 1969-1979). São Paulo: Marco Zero, 1992.

SARMENTO, Manuel Jacinto. Gerações e alteridade: interrogações a partir da sociologia da infância. Educação Social, Campinas, v. 26, n. 21, p. 361-378, mai./ago. 2005.

SIMMEL, G. As grandes cidades e a vida do espírito (1903). Revista Mana, v. 11, n. 2, p. 577-591, 2005. Disponível em:

$<$ http://www.scielo.br/scielo.php?script=sci_arttext\&pid=S0104-93132005000200010>. Acesso em: 17 mai. 2012.

STEINBERG, Shirley. Kindercultura: a construção da infância pelas grandes corporações. In: SILVA, Luiz Heron; AZEVEDO, José Clóvis de; SANTOS, Edimilson Santos dos (Orgs.). Identidade social e a construção do conhecimento. Porto Alegre: PMPA, 1997. p. 98-145.

STIGGER, Marco Paulo. Lazer, cultura e educação: possíveis articulações. Revista Brasileira de Ciências do Esporte, Campinas, v. 30, n. 2, p. 57-72, jan. 2009.

VAZ, Alexandre Fernandez. Educação, experiência, sentido do corpo e da infância (um estudo experimental em escritos de Walter Benjamim. In: PAGNI, P. A; PELLOSO, R. G. (org.). Experiência, educação e contemporaneidades. São Paulo: Cultura Acadêmica, 2010. p. 35-50.

VEIGA-NETO, Alfredo. Espaço e currículo. In: LOPES, Aline Casimiro; MACEDO, Elizabeht (Org.) Disciplinas e integração curricular: história e políticas. Rio de Janeiro: DP\&A, 2002. p. 201-220. 
WEEKS, Jeffrey. O corpo e a sexualidade. In: LOURO, Guacira Lopes. O corpo educado: pedagogias da sexualidade. Belo Horizonte: Autêntica Editora, 1999. p. 3582.

WENETZ, Ileana. Gênero e sexualidade nas brincadeiras do recreio. 2005.

Dissertação (Mestrado em Ciências do Movimento Humano) - Programa de Pós-

Graduação em Ciências do Movimento Humano, Escola de Educação Física Universidade Federal do Rio Grande do Sul, Porto Alegre, 2005.

. Presentes na escola e ausentes na rua: brincadeiras de crianças marcadas pelo gênero e pela sexualidade. 2012. Tese (Doutorado em Ciências do Movimento Humano) - Programa de Pós-Graduação em Ciências do Movimento Humano, Escola de Educação Física, Universidade Federal do Rio Grande do Sul - Porto Alegre, 2012.

Recebido em: 20/10/2019

Aceito em: 10/11/2019 